\title{
Treatment outlines for Australian psychiatry: an overview of the project
}

\author{
GAVIN ANDREWS
}

Clinical meetings are a tradition in medicine. They are a forum where difficult cases are reviewed and new developments discussed. Such meetings are common in hospital practice but doctors who work in solo or office practice are often isolated from such ways of keeping up to date. In 1980 the Australian Government was pressing the medical specialists' organisations to develop methods for ensuring optimal standards for clinical practice. The psychiatrists' organisation, The Royal Australian and New Zealand College of Psychiatrists, decided that the first step in their response would be to formulate a set of treatment outlines for use in peer review. The Quality Assurance Project was seen as the mechanism for developing the treatment outlines.

The Quality Assurance Project research team decided that three sources of information should be used - literature reviews, surveys of current practice and the opinions of designated experts. The literature review analysed the results of English language randomised placebo controlled trials using Glass's (1976) meta-analytic procedure. When only pre-post data were available the quantitative meta-analytic procedure was still used, but for disorders in which no body of clinical trials existed (e.g. the somatoform and personality disorders) we had to return to the usual qualitative literature review. Current practice was researched by having a one in six nationwide sample of psychiatrists complete a series of structured questionnaires that asked about their probable treatment plans for 25 patients whose symptoms and diagnoses were described in 400 word case histories. The response to this survey was very high and compliance rates

Indirizzo per la corrispondenza: Professor Gavin Andrews, University of New South Wales at St. Vincents Hospital, Anxiety Disorders Unit, 299 Forbes Street, Darlinghurst, NSW. 2010 (Australia).

Fax: (+61) 2-332.4316. approached $90 \%$. Leaders of the profession were then asked to nominate persons expert in the treatment of each disorder and then vote on the consolidated list. Committees of persons elected as expert in each disorder were then convened (none declined) to consider the results of the literature review and the practice survey before preparing their recommendations about the treatment of each disorder.

Ten treatment outlines were subsequently published. One each on depression (Quality Assurance Project, 1983) schizophrenia (Quality Assurance Project, 1984) and somatoform disorder (Quality Assurance Project, 1985a), three on the anxiety disorders (Quality Assurance Project, 1982; 1985b; 1985c) and four on the personality disorders (Quality Assurance Project, 1990; 1991a; 1991b; 1991c) (Copies are available from the author). Each treatment outline contained an introduction that discussed the criteria for diagnosis (usually in DSM-III terms, ICD-10 not being available at that time) and gave a brief review of the epidemiology and etiology of the disorder. The results of the literature survey and the survey of current practice were then presented. These two sources of information were followed by, but remained separate to, the expert committee's recommendation about treatment.

In retrospect, the parts of each treatment outline have differed in importance. The literature reviews were in advance of their time. While meta-analytic reviews are now commonplace, those for schizophrenia, for depression and for the anxiety disorders were original, the first revealing the effectiveness of psychoeducation when used with anti-psychotic drugs, the second for revealing the benefits of antidepressants in neurotic depression, while the anxiety disorder meta-analyses were of sufficient value to be subsequently expanded and published independently (Christensen et al., 1987; Mattick et al. 1990). 
The surveys of what treatments practicing psychiatrists would recommend for patients with schizophrenia, depression and for the anxiety and somatoform disorders were also published independently (Hall et al., 1982; Andrews et al., 1986; Armstrong \& Andrews, 1986; Andrews et al., 1987). They form the first systematic account of what psychiatrists thought would be appropriate treatment for patients with these diagnoses. We subsequently surveyed the actual work (Andrews \& Hadzi-Pavlovic, 1988), rather than the opinions, of these psychiatrists. We believe, from a pilot interview study and from independent data, that the results of this workload study were valid. The findings were that these psychiatrists tended to carry out the treatments they had recommended in the earlier survey, and that their caseload reflected, as one would hope, a combination of prevalence and severity of the various disorders in the community (psychosis $41 \%$, neurosis $39 \%$, personality disorder $6 \%$, disorders of children $7 \%$, marital disorders and «V» codes 6\%).

When analysed by type of practice the picture changed. Psychiatrists in the public sector tended to focus on hospital based care of psychotic patients while those in private practice tended to be biased towards long term dynamic psychotherapy. The hours this latter group estimated spending in therapy before the patient recovered were considerably more than expected from the literature; depression (178 hours), anxiety and phobia (262 hours), and personality disorders (520 hours) (Andrews et al., 1987; Andrews \& Hadzi-Pavlovic, 1988). It was subsequently argued that as dynamic psychotherapy had not been shown to be superior to placebo, was expensive and could be harmful (Andrews, 1991a), that this preoccupation of private sector psychiatrists with dynamic psychotherapy represented a wrongful use of health care resources (Andrews, 1993). Australia seems to be the only country in which a national health insurance scheme provides unlimited fee-for-service reimbursment for long term private sector psychotherapy.

In subsequent papers, also derived from the work of the Quality Assurance Project, the organisation of psychiatry in Australia was described and the likely costs of direct treatment compared with those prevailing in New Zealand, USA and the United Kingdom (Andrews, 1990). Three factors leading to changes in the traditional role of the psychiatrist as the central figure in the delivery of mental health services were identified (Andrews, 1991b). These were the advent of structured diagnostic interviews, such as the Composite International Diagnostic Interview, which mean that the diagnosing of patients with mental disorders is no longer the exclusive preserve of psychiatrists. Second, the deinstitutionalisation of mental health care (Australia now has 50 beds per 100,000 head of population, one of the lowest figures in the developed world) means that general practitioners and community mental health staff are increasingly responsible for diagnosing and treating the majority of persons with mental disorders. Last, the identification of private psychiatrists with the dynamic psychotherapies has been noted by the media and they have identified other professional groups with the less expensive and more effective cognitive behaviour therapies, producing a corresponding shift in the public perception of the importance of the psychiatric profession.

Despite these problems in service delivery the key question remains; did the treatment outlines influence standards of psychiatric practice? There is no empirical way to find this out. The College has not begun a nationwide system of peer review which was the original intention behind the project, simply because it is too difficult to implement an effective model of peer review in private practice. The project has made many psychiatrists more confident that what they do is effective and supported by expert opinion and controlled research. The treatment outlines are used to inform clinical meetings and for some years they were learned diligently by all psychiatrists in training, if only because the examiners tended to have been members of the expert committees. The quality of the treatment advice in the outlines does vary. Some are excellent (e.g. schizophrenia, depression, somatoform disorder) and are exactly what textbooks of psychiatry should include, other outlines (e.g. obsessive compulsive disorders) show evidence of the committee process whereby the views of all experts, no matter how diverse, had to be represented. Nevertheless all outlines make a significant contribution to the art of treatment reconciling facts about treatment efficacy with ideas of current practice and with clinical wisdom of the experts. As director of the project and amanuensis to the expert committees I was educated by contributions that each sector of our profession made, whether the expert viewpoint came from pharmacotherapy, cognitive behaviour therapy, psychoanalysis or just good clinical care.

There were costs associated with the project. First the dynamic psychotherapists opposed the project from the outset for exactly the same reason as they opposed Spitzer as he organised the DSM project (Bayer \& Spitzer, 1985); they were outraged that a 
phenomenological system of diagnosis could be used to structure psychiatric practice. They remained ambivalent about the project but eventually collaborated and contributed heavily to the treatment outlines for personality disorders. The monetary costs of the project were relatively small, about 2.3 person years per treatment outline. One anticipated cost did not eventuate. We were all worried that the legal profession would seize upon these outlines as prescriptive and challenge doctors who treated patients in other ways. This type of legal action has not occurred in Australia, although concern over such a possibility was one factor in aborting a similar project in the United Kingdom.

Few ideas are truly original. The idea of producing a consensus position about treatment was used by the US National Institute of Mental Health for ECT in the late 1970's. Soon after the present Australian project began the American Psychiatric Association, with Byram Karasu as chair, commenced what appeared to be a similar exercise. To the outsider it appears that three volume opus approved a great number of therapies, and hence was not so much an evaluation, as a comprehensive listing for the members of the Association. Norman Sartorius convened a WHO scientific group on the evaluation of methods for the treatment of mental disorders in 1989. Experts from around the world were asked to forward position papers and then the scientific committee summarised them in the technical report (WHO Scientific Group, 1991). The position papers were later published (Andrews, 1992; Sartorius et al., 1993). The US National Institutes of Health have recently convened another series of consensus conferences. In my view such efforts are only properly useful if the evidence in the literature is summarised and then illuminated by the views of experts. When they are melded together as dogma it is difficult to distinguish the science from the art of treatment. This is important for, as science only issues interim reports, the scientific basis of treatment may change from decade to decade. On the other hand, as the predicament of someone suffering from depression or schizophrenia or a phobia does not change from one decade to another, the art of treatment is likely to be more enduring, harder to teach, and probably more valuable to the practice of psychiatry than simple information about the specifics of treatment.

\section{REFERENCES}

Andrews G. (1990). Health services research and the future of Australian Psychiatry. Australian and New Zealand Journal of Psychiatry 24, 371-376.

Andrews G. (1991a). The evaluation of psychotherapy. Current Opinion in Psychiatry 4, 379-383.

Andrews G. (1991b). The changing nature of psychiatry. Australian and New Zealand Journal of Psychiatry 25, 453-459.

Andrews G. (1992). Which treatments are of benefit? Methods for assessing treatment techniques. International Journal of Mental Health 21, 11-23.

Andrews G. (1993). The essential psychotherapies. British Journal of Psychiatry 162, 447-451.

Andrews G. \& Hadzi-Pavlovic D. (1988). The work of Australian psychiatrists, circa 1986. Australian and New Zealand Journal of Psychiatry 22, 153-165.

Andrews S., Vaughan K., Harvey R. \& Andrews G. (1986). A survey of practising psychiatrists' views on the treatmeni of schizophrenia. British Journal of Psychiatry 149, 357-364.

Andrews G., Hadzi-Pavlovic D., Christensen H. \& Mattick R. P. (1987). Views of practicing psychiatrists on the treatment of anxiety and somatoform disorders. American Journal of Psychiatry 144, 1331-1334.

Armstrong M. S. \& Andrews G. (1986). A survey of practising psychiatrists' views on treatment of the depressions. British Journal of Psychiatry 149, 742-750.

Bayer R. \& Spitzer R. L. (1985). Neurosis, psychodynamics, and DSM-III. A history of the controversy. Archives of General Psychiatry 42, 187-196.

Christensen H., Hadzi-Pavlovic D., Andrews G. \& Mattick R. P. (1987). Behaviour therapy and tricyclic medication in the treatment of obsessive compulsive disorder: a quantitative review. Journal of Consulting and Clinical Psychology 55, $701-711$.

Glass G. V. (1976). Primary, secondary and meta-analysis of research. Educational Researcher 10, 3-8.

Hall W., Weekes P., Harvey R. \& Andrews G. (1982) A survey of practising psychiatrists' views on the treatment of agoraphobia. Australian and New Zealand Journal of Psychiatry $16,225-233$.

Mattick R., Andrews G., Hadzi-Pavlovic D. \& Christensen H. (1990). Treatment of panic and agoraphobia: an integrative review. Journal of Nervous and Mental Disease 178, 567-576.

Quality Assurance Project (1982). A treatment outline for agoraphobia. Australian and New Zealand Journal of Psychiatry $16,25-33$.

Quality Assurance Project (1983). A treatment outline for depressive disorders. Australian and New Zealand Journal of Psychiatry 17, 129-148.

Quality Assurance Project (1984). Treatment outlines for the management of schizophrenia. Australian and New Zealand Journal of Psychiatry 18.

Quality Assurance Project (1985a). Treatment outlines for the management of the somatoform disorders. Australian and New Zealand Journal of Psychiatry 19, 397-407.

Quality Assurance Project (1985b). Treatment outlines for the management of anxiety states. Australian and New Zealand Journal of Psychiatry 19, 138-151.

Quality Assurance Project (1985c). Treatment outlines for the management of obsessive compulsive disorders. Australian and New Zealand Journal of Psychiatry 19, 240-253. 


\section{G. Andrews}

Quality Assurance Project (1990). Treatment outlines for the paranoid, schizotypal and schizoid personality disorders. Austra lian and New Zealand Journal of Psychiatry 24, 339-350.

Quality Assurance Project (1991a). Treatment outlines for the borderline, narcissistic and histrionic personality disorders. $A u$ stralian and New Zealand Journal of Psychiatry 25, 392-403.

Quality Assurance Project (1991b), Treatment outlines for the avoidant, dependent and passive-aggressive personality disorders. Australian and New Zealand Journal of Psychiatry 25, 404-411.
Quality Assurance Project (1991c). Treatment outlines for antisocial personality disorder. Australian and New Zealand Journal of Psychiatry 25, 541-547.

WHO Scientific Group (1991). Evaluation of Methods for the Treatment of Mental Disorders. WHO Technical Report Series, No. 812.

Sartorius N., de Girolamo G., Andrews G. German A. \& Eisenberg L. (1993) Treatment of Mental Disorders: A Review of Effectiveness (World Health Organisation). American Psychiatric Press Incorporated: Washington. 